\title{
Meeting Report: 9th Annual Diabetes Nepal Conference
}

\author{
Satyan Rajbhandari \\ Lancashire Teaching Hospital, Preston Road, Chorley, UK
}

9th Annual Diabetes Nepal Conference and Indo-Nepal-UK Diabetes Meeting was held in Kathmandu on 23rd February 2019. This was preceded by Regional Diabetes Update in Butwal on 20th February, which was attended by 30 doctors working in the south western part of Nepal. An educational update for nurses and nutritionist was also conducted in Padma Kanya Campus, Kathmandu on 22nd February 2019 that was attended by 84 participants.

Dr Mrigendra Raj Pandey inaugurated the ceremony in the morning of 23rd February at Hotel Annapurna. During this the 'Life Time Achievement Award' was presented to Dr Ishwor Lal Acharya, for his contribution to improve awareness and management of diabetes in Nepal. The meeting was attended by 160 participants. This meeting was supported from unrestricted educational grant by USV and was approved by the Federation of the Royal College of Physicians of the UK for 6 CPD points.

Dr Mark Savage from Australia presented a paper on cardiovascular risk of diabetes and how to manage them with old and new drugs. Dr Manilka Sumanatilleke from Sri Lanka presented a paper on diabetic neuropathy and explained that this common but frequently unrecognised complication can be effectively managed to improve patient wellbeing. This was followed by a paper by Dr Debmalya Sanyal from India on a rising trend of post-transplant diabetes and how to manage it. Dr Martin Myers from the UK presented paper on how to monitor diabetes control and highlighted the issues with possible pitfalls in $\mathrm{HbA1c}$ measurement. Dr Robin Maskey from Nepal gave useful insights into why there are barriers to introduction of new treatment in Nepal and why patients and doctors are reluctant to start insulin therapy.
Following lunch Dr Vijay Poudel from Nepal gave very useful tips on the management of NG tube feeding in diabetes. This was followed by an exciting paper by Dr Basil Issa of the UK on how remission of diabetes can be achieved by various methods of weight loss. He presented data from recent studies and proposal of new research. Dr Abha Shrestha and Mrs Pushpanjali Shakya from Nepal ran an interactive session on how to empower people to look after their own diabetes. Mrs Pam Savage from Australia ran a workshop on how to examine diabetic foot and how to manage ulcers. Dr Satyan Rajbhandari and Mrs Nani Shova Shakya ran a light hearted interactive session on misconception about diet and exercise in managing diabetes in Nepal.

The feedback for the meeting was very good and was concluded with symposium dinner. The 10th Annual Diabetes Nepal Conference will be held in Kathmandu on 4th April 2020. During that time the Regional meeting and the meeting for paramedical staffs will be held in Dharan before the main symposium. Dr Robin Maskey will organise the regional meeting in Dharan.

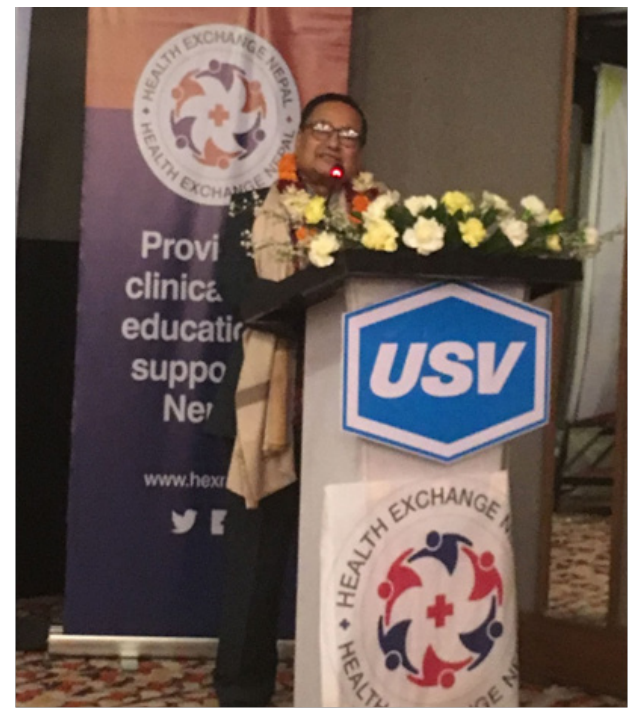




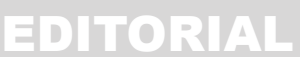

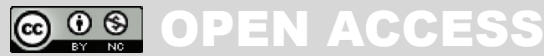

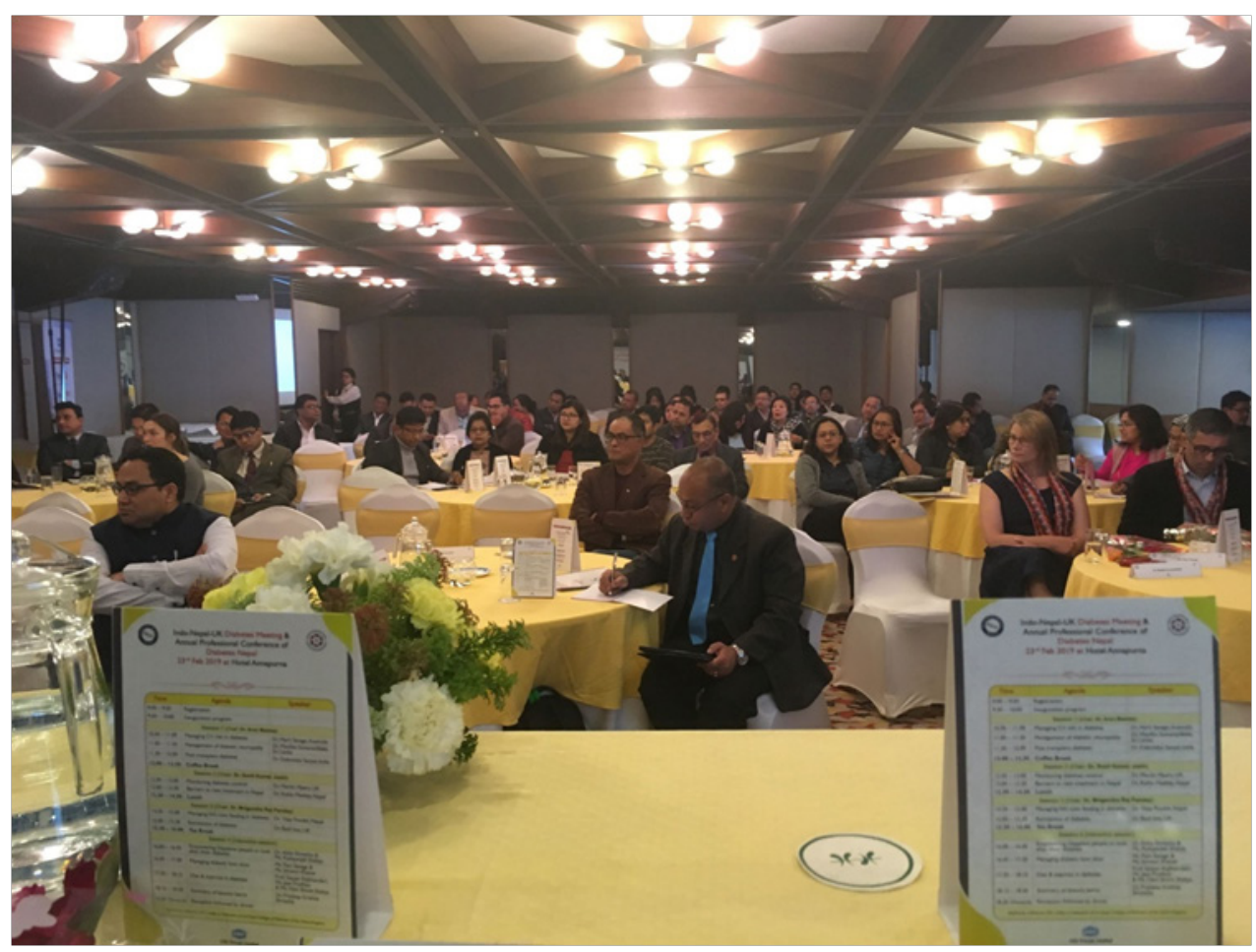

Participants of the meeting

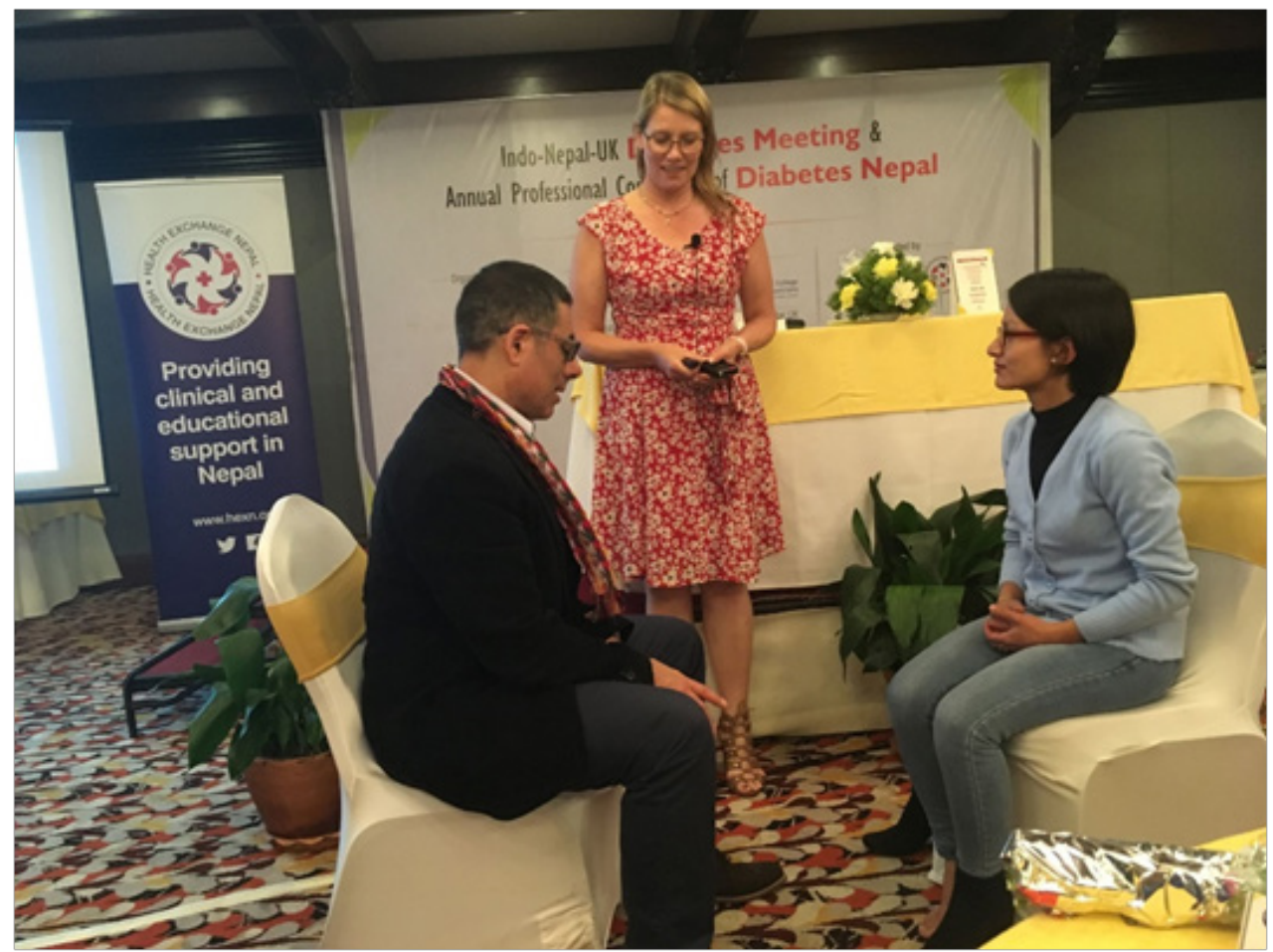

Workshop in foot care 